\title{
PHYSICAL ACTIVITY AND SCREEN-BASED ACTIVITY IN HEALTHY DEVELOPMENT OF SCHOOL-AGED CHILDREN
}

\author{
Zdeněk Hamřík', Daniela Bobáková2, ${ }^{3,4}$, Michal Kalman¹, Zuzana Dankulincová Veselská2, ${ }^{2}$, Daniel Klein ${ }^{5}$, Andrea \\ Madarasová Geckováa, 3,4 \\ ${ }^{1}$ Department of Recreation and Leisure Studies, Faculty of Physical Culture, Palacký University Olomouc, Olomouc, Czech Republic \\ ${ }^{2}$ Graduate School Košice Institute for Society and Health, Šafárik University in Košice, Košice, Slovak Republic \\ ${ }^{3}$ Department of Health Psychology, Medical Faculty, Šafárik University in Košice, Košice, Slovak Republic \\ ${ }^{4}$ Olomouc University Social Health Institute, Palacký University Olomouc, Olomouc, Czech Republic \\ ${ }^{5}$ Institute of Mathematics, Science Faculty, Šafárik University in Košice, Košice, Slovak Republic
}

\section{SUMMARY}

Aim: Physical and screen-based activity in adolescents plays a crucial role in future health outcomes. Therefore, the aim of the study was to examine the associations of physical activity and screen-based activity with behavioural and psychosocial characteristics of school-aged children.

Methods: Data on 11,13 and 15 years old elementary school pupils $(N=9,014$; mean age $=13.59)$ who participated in the cross-sectional Health Behaviour in School-aged Children 2009/2010 study in the Czech Republic and the Slovak Republic were analyzed. The associations of vigorous physical activity and screen-based activity with substance use, violent behaviour, eating habits and school-related outcomes adjusted for age were explored using logistic regression.

Results: Vigorous physical activity was positively associated with some of the health-related behaviours (smoking, breakfast consumption, vegetable and fruit consumption) and school related outcomes (perceived school achievement and school pressure), with gender and country based differences. Screen-based activity was significantly associated with all examined health-related behaviours and school related outcomes with only some country and gender based differences.

Conclusions: Vigorous physical activity is positively associated with healthy development of adolescents. Screen-based behaviour shows an inverse relationship with adolescents' healthy development, especially in the group of 11 and 13 years old children. Supporting physical activity conducive environments might lead to a reduction in screen-based behaviour in adolescents and should be highlighted in health-promoting strategies.

Key words: adolescents, vigorous physical activity, screen-based activity, risky and aggressive behaviour, eating habits, school-related outcomes

Address for correspondence: Z. Hamrík, Department of Recreation and Leisure Studies, Faculty of Physical Culture, Palacký University Olomouc, Tř. Míru 115, 77111 Olomouc, Czech Republic. E-mail: zdenek.hamrik@hbsc.org

\section{INTRODUCTION}

The increasing rate of sedentary behaviour accompanied by a worldwide decline in physical activity among adults (1) leads to an increased prevalence of overweight and obese individuals in the population $(2,3)$. A similar picture can be found among schoolaged children (4-6). Most children do not meet the recommended levels of physical activity (7) and the number of overweight and obese children is increasing (8-10). The prevalence of overweight and obese children has serious physical (skeletal, muscular, cardiovascular system), psychological (self-esteem, depression) and social (team integration) health consequences (11-13) that can progress into adulthood (14).

Furthermore, sedentary behaviour (SB) in children, which usually refers to leisure-time activity (15) has been recognised as a serious public health issue in the past ten years (16). Most children watch television for two or more hours on weekdays (7). The structure of SB, however, has changed rapidly over the last few years. While Pratt et al. (17) considered watching TV to be the main indicator of sedentary behaviour, 10 years later Biddle et al. (18) or Sigmundová et al. (19) pointed out that this area also includes a wide range of sedentary activities, and research in this field should not be focused solely on television viewing. The use of computers either for gaming or chatting, emailing or surfing the internet outweighs the total amount of time spent watching television. SB together with low levels of physical activity have become a major risk factor in the onset of chronic non-communicable diseases and play a crucial role in future health outcomes $(20,21)$.

Adolescence is an important period of psychosocial development, during which important behavioural and psychosocial lifestyle characteristics are established through experimentation (22). Van Nieuwenhuijzen et al. (23) suggested the process of establishing clusters by behavioural characteristics in adolescence, which, from 19 years of age, becomes stable. Different types of problem behaviour are highly correlated and predicted by each other, and have many of the same risk and protective factors (24).

Therefore, we can expect that the coincidence or association of certain kinds of behaviour (e.g. physical activity or screenbased activity) with some aspects of behaviour and psychosocial development (e.g. violent behaviour or attitude towards school) 
could indicate a direction of development and might be a nucleus of future psychosocial and behavioural characteristics of a given individual.

The aim of the study was to examine the associations of vigorous physical activity and screen-based activity with substance use, violent behaviour, dietary habits and school-related outcomes in school-aged children.

\section{MATERIALS AND METHODS}

The study sample consisted of subjects taking part in the crosssectional Health Behaviour in School-aged Children (HBSC) study conducted in the Czech and Slovak Republics in 2010 (N=9,014; mean age $=13.59$ ). School and student participation in the study was fully voluntary; students completed the questionnaire anonymously with no explicit incentives provided for participation. Hardcopy questionnaires were administered to students by trained research assistants during regular class time always in the absence of a teacher. All of the questions used in the HBSC survey must have evidence of reliability and validity when used in multiple countries before they are considered for inclusion (25).

\section{Slovak Republic}

From a list of schools based on the information provided by the Slovak Institute of Information and Prognosis for Education, 134 larger and smaller schools located in rural as well as in urban areas from all regions of Slovakia were randomly chosen to create a representative sample. Out of 108 contacted schools, 106 schools took part in our survey, representing a $98.1 \%$ school response rate. Classes from the 5 th to 9 th grades were selected randomly, one from each grade per school. We obtained data from 8,491 adolescents from the 5 th to 9 th grade (response rate $79.5 \%$ ). Nonresponse $(20.5 \%)$ was primarily due to illness $(10.3 \%)$ and parental disapproval of the participation of their children (7.4\%). For the purposes of the paper, adolescents at the age of 11 years $(n=1,259)$, 13 years $(n=1,746)$, and 15 years $(n=1,605)$ were analyzed. The final sample consisted of 4,610 Slovak pupils ( $48 \%$ boys).

\section{Czech Republic}

Ninety-one schools from all 14 regions were chosen to create a representative sample in the Czech Republic. Schools were randomly selected from a list of schools based on the information submitted by the Institute for Information on Education, a state-funded organization of the Ministry of Education, Youth and Sport. We contacted 91 schools, and 86 schools took part in our survey, representing a $94.5 \%$ school response rate. According to the HBSC study protocol, classes from 5th to 9th grades were selected randomly, one from each grade per school. We obtained data from 5,284 adolescents from 5th, 7th and 9th grade of elementary schools in the Czech Republic (response rate 87\%). Non-response due to absence was $13 \%$ ( 786 pupils). The number of absent adolescents due to illness was not available. The total sample consisted of 4,404 Czech adolescents ( $49 \%$ boys) at the age of 11 years $(n=1,404), 13$ years $(n=1,456)$ and 15 years $(n=1,522)$.

The study was performed according to the ethical requirements formulated by the Agreement on Human Rights and Biomedicine
(40/2000 Coll.) and under the principles of the Helsinki Declaration and legal and regulatory requirements applicable to both countries. The study in Slovakia was approved by the Ethics Committee of the Medical Faculty at the Pavol Jozef Šafárik University in Košice. The parents were informed about the study via school administration and could opt out if they wished. The study in the Czech Republic was approved by the Ministry of Health and the National Institute of Public Health.

\section{Measures}

A more detailed description and validation of all the measures used in our study can be found in the HBSC 2009/2010 international study protocol (26).

Vigorous physical activity. Students were asked how often (outside school hours) they usually do exercise in their free time which makes them to get out of breath or sweat with possible responses of every day; 4 to 6 times a week; 2 to 3 times a week; once a week; once a month; less than once a month; never. Engagement in such activity for at least 2-3 times a week was considered to be "vigorous physical activity".

Screen-based activity. Students were asked how many hours a day during weekdays they usually spend watching television, playing games on a computer or games console and using a computer for chatting on-line, internet, emailing, homework, etc. in their free time, where the response of six or more hours of such activity per day was considered to be "screen-based activity".

Smoking cigarettes. Students indicated how often they currently smoke cigarettes with possible responses of I do not smoke; less than once a week; at least once a week, but not every day; every day. Smoking at least once a week was categorised as "smoking at least weekly".

Drunkenness. The question was preceded by a definition of "really drunk". Students reported whether they had ever had so much alcohol that they were "really drunk" with possible responses of never; once; 2-3 times; 4-10 times; more than 10 times. Reporting drunkenness at least 2-3 times was categorised as "lifetime drunkenness ( $\geq 2$ times)".

Bullying. The question was preceded by a definition of bullying. Students responded how often they had taken part in bullying another student(s) at school in the past couple of months with possible responses of I have not bullied another student(s) at school in the past couple of months; it has only happened once or twice; 2 or 3 times a month; about once a week; several times a week. Reporting such behaviour at least 2-3 times a month was categorised as "bullying others".

Physical fighting. Students were asked how many times during the last 12 months they had been involved in a physical fight with possible responses of I have not been in a physical fight in the past 12 months; 1 time; 2 times; 3 times; 4 times or more. Fighting at least 3 times during the last 12 months was categorised as "frequent fighting".

Breakfast consumption. Students reported how often they eat breakfast on school days (more than a glass of milk or fruit juice) with possible responses of I never have breakfast during the week; one day; two days; three days; four days; five days. Having breakfast 5 days a week was categorised as "regular breakfast on weekdays".

Food frequency. Students indicated how often they eat fruit, vegetables, sweets and Coke or other soft drinks that contain sugar 
with possible responses of never; less than once a week; once a week; 2-4 days a week; 5-6 days a week; once a day, every day; every day more than once. Consumption frequencies at least once a day, every day were categorised as "daily fruit, vegetable, sweets or soft drinks consumption".

Perceived school performance. Students were asked what, in their opinion, their class teacher(s) thinks about their school performance compared with their classmates with possible responses of very good; good; average; below average. Good or very good perceived school performance were categorised as "good perceived school performance".

Liking school. Students indicated how they feel about school at present with possible responses of I like it a lot; I like it a bit; I don't like it very much; I don't like it at all. The first two categories were categorised as "liking school".

Pressured by school. Students responded how pressured they feel by the schoolwork they have to do with possible responses of not at all / a little / some / a lot. Some or a lot of perceived school pressure were categorised as "pressured by school".

Socioeconomic status (SES). SES was measured using the Family Affluence Scale II (FAS II), which consists of four questions: How many computers does your family own (none; one; two; more than two)? Does your family own a car, van or truck (no/ yes, one/yes, two or more)? Do you have your own bedroom for yourself (no/yes)? During the past 12 months, how many times did you travel away on holiday with your family (not at all; once; twice; more than twice)? The sum score was computed, and a three-point ordinal scale was used in the analysis: low SES (score $=0-3)$, medium SES (score = 4-6) and high SES (score = 7-9).

\section{Statistical Analyses}

Firstly, descriptive statistics for background characteristics among Slovak and Czech boys and girls were computed. Next, we assessed the association of vigorous physical activity (VPA) and screen-based activity (SBA) with adolescents' substance use, violent behaviour, eating habits and school-related outcomes, adjusted for age and socioeconomic status (SES) using logistic regression. Since we found statistically significant country differences regarding all of the covariates and significant gender difference regarding vigorous physical activity, the models were constructed separately for the Czech Republic and the Slovak Republic and for boys and girls. Furthermore, we assessed the interaction of country and age with VPA and SBA regarding risky behaviour, aggressive behaviour, eating habits and the school-related outcomes concerned. We tested the significance of the interactions by comparing the fit $(-2$

Table 1. Descriptive statistics by country

\begin{tabular}{|c|c|c|c|}
\hline & Slovak Republic $(N=4,610)$ & Czech Republic $(\mathrm{N}=4,404)$ & \multirow{2}{*}{ p-value* } \\
\hline & $\mathrm{n}(\%)$ & $\mathrm{n}(\%)$ & \\
\hline \multicolumn{4}{|l|}{ Gender } \\
\hline Boys & $2,225(48.3)$ & $2,135(48.5)$ & \multirow{2}{*}{ ns } \\
\hline Girls & $2,385(51.7)$ & $2,269(51.5)$ & \\
\hline \multicolumn{4}{|l|}{ Socioeconomic status } \\
\hline Low & $1,048(25.5)$ & $640(15.1)$ & \multirow{3}{*}{$<0.001$} \\
\hline Middle & $2,065(50.3)$ & $2,464(58.0)$ & \\
\hline High & $996(24.2)$ & $1,146(27.0)$ & \\
\hline Vigorous physical activity & $2,936(63.7)$ & $3,222(73.2)$ & $<0.001$ \\
\hline Screen-based activity & $2,638(57.2)$ & $1,874(42.6)$ & $<0.001$ \\
\hline \multicolumn{4}{|l|}{ Risky behaviour } \\
\hline Smoking at least weekly & $457(9.9)$ & $542(12.3)$ & $<0.001$ \\
\hline Lifetime drunkenness ( $\geq 2$ times) & $767(16.6)$ & $978(22.2)$ & $<0.001$ \\
\hline \multicolumn{4}{|l|}{ Aggressive behaviour } \\
\hline Bullying others ( $\geq 2$ times a month) & $638(13.8)$ & $150(3.4)$ & $<0.001$ \\
\hline Frequent fighting ( $\geq 3$ times a year) & $663(14.4)$ & $708(16.1)$ & $<0.05$ \\
\hline \multicolumn{4}{|l|}{ Eating habits } \\
\hline Regular breakfast on weekdays & $2,329(50.5)$ & $2,344(53.2)$ & $<0.01$ \\
\hline Daily fruit consumption & $1,546(33.5)$ & $1,837(41.7)$ & $<0.001$ \\
\hline Daily vegetables consumption & $1,189(25.8)$ & $1,396(31.7)$ & $<0.001$ \\
\hline Daily sweets consumption & $1,961(42.5)$ & $1,210(27.5)$ & $<0.001$ \\
\hline Daily soft drinks consumption & $1,640(35.6)$ & $975(22.1)$ & $<0.001$ \\
\hline \multicolumn{4}{|l|}{ School related } \\
\hline Good perceived school achievement & $3,105(67.4)$ & $2,451(55.7)$ & $<0.001$ \\
\hline Liking school & $2,890(62.7)$ & $3,249(73.8)$ & $<0.001$ \\
\hline Pressured by school & $961(20.8)$ & $1,502(34.1)$ & $<0.001$ \\
\hline
\end{tabular}

*chi-square statistics; ns - not significant 
log likelihood) of the models with and without interaction. The analyses were performed using SPSS 18.0 for Windows.

\section{RESULTS}

Czech adolescents reported significantly more frequent VPA and significantly less frequent SBA compared with their Slovak counterparts (Table 1). They also reported significantly more frequent substance use (weekly smoking, lifetime drunkenness), fighting, healthier eating habits, a positive attitude towards school and being pressured by school compared with Slovak adolescents (Table 1).

On the other hand, Czech adolescents reported significantly less frequent bullying others and good perceived school achievement than Slovak adolescents (Table 1).
Table 2 shows the association of VPA and SBA with adolescents' substance use, violent behaviour, eating habits and schoolrelated outcomes, adjusted for age.

VPA reported by adolescents significantly decreased the probability of adolescents smoking in both countries, but only among girls. On the contrary, SBA significantly increased the probability of adolescents smoking, but only among Czech adolescents. VPA did not contribute to lifetime drunkenness but SBA significantly increased its probability in both countries and genders.

VPA significantly increased the probability of frequent fighting among Czech boys; otherwise it did not contribute to violent behaviour in adolescents. On the other hand, SBA significantly increased the probability of violent behaviour, bullying others as well as frequent fighting in both countries and both genders.

Regarding healthy eating habits, VPA increased the probability of regular breakfast consumption and daily fruit and vegetable

Table 2. Associations of vigorous physical activity (VPA) and screen-based activity (SBA) with risky behaviour, eating habits, school-related outcomes, and aggressive behaviour adjusted for age and SES, odds ratios (OR) and 95\% confidence intervals (CI)

\begin{tabular}{|c|c|c|c|c|c|}
\hline & & \multicolumn{2}{|c|}{ Slovak Republic } & \multicolumn{2}{|c|}{ Czech Republic } \\
\hline & & Boys & Girls & Boys & Girls \\
\hline & & OR $(95 \% \mathrm{Cl})$ & $\mathrm{OR}(95 \% \mathrm{Cl})$ & OR $(95 \% \mathrm{Cl})$ & OR $(95 \% \mathrm{Cl})$ \\
\hline \multicolumn{6}{|l|}{ Risky behaviour } \\
\hline \multirow{2}{*}{ Smoking at least weekly } & VPA & $0.79(0.58-1.07)$ & $0.61(0.45-0.84)^{\star *}$ & $0.94(0.67-1.31)$ & $0.76(0.58-0.99)^{*}$ \\
\hline & SBA & $0.99(0.74-1.32)$ & $0.77(0.56-1.06)$ & $1.93(1.43-2.60)^{\star \star \star}$ & $2.39(1.83-3.11)^{\star * *}$ \\
\hline \multirow{2}{*}{ Lifetime drunkenness ( $\geq 2$ times) } & VPA & $0.83(0.64-1.06)$ & $0.93(0.74-1.18)$ & $1.13(0.87-1.48)$ & $1.07(0.84-1.37)$ \\
\hline & SBA & $1.86(1.45-2.38)^{\star \star \star}$ & $1.98(1.55-2.52)^{\star \star \star}$ & $1.69(1.35-2.11)^{\star * *}$ & $2.20(1.74-2.78)^{\star \star \star}$ \\
\hline \multicolumn{6}{|l|}{ Aggressive behaviour } \\
\hline \multirow{2}{*}{ Bullying others ( $\geq 2$ times a month) } & VPA & $0.97(0.74-1.27)$ & $0.96(0.75-1.24)$ & $1.09(0.63-1.88)$ & $1.47(0.82-2.63)$ \\
\hline & SBA & $1.51(1.17-1.96)^{* *}$ & $1.42(1.10-1.82)^{\star *}$ & $1.88(1.19-2.98)^{* *}$ & $1.86(1.12-3.10)^{*}$ \\
\hline \multirow{2}{*}{ Frequent fighting ( $\geq 3$ times a year) } & VPA & $0.89(0.68-1.17)$ & $0.97(0.76-1.25)$ & $1.39(1.08-1.78)^{\star}$ & $0.98(0.67-1.45)$ \\
\hline & SBA & $2.36(1.79-3.10)^{* * *}$ & $1.70(1.32-2.19)^{* * *}$ & $1.65(1.35-2.02)^{* \star *}$ & $1.65(1.15-2.38)^{* \star}$ \\
\hline \multicolumn{6}{|l|}{ Eating habits } \\
\hline \multirow{2}{*}{ Regular breakfast on weekdays } & VPA & $0.98(0.81-1.19)$ & $0.90(0.76-1.07)$ & $1.42(1.15-1.77)^{\star \star}$ & $1.24(1.03-1.49)^{*}$ \\
\hline & SBA & $0.69(0.58-0.83)^{\star * *}$ & $0.69(0.58-0.82)^{* * *}$ & $0.59(0.49-0.70)^{\star \star \star}$ & $0.59(0.49-0.70)^{\star * \star}$ \\
\hline \multirow{2}{*}{ Daily fruit consumption } & VPA & $1.02(0.83-1.25)$ & $1.09(0.91-1.31)$ & $1.83(1.44-2.33)^{\star \star *}$ & $1.70(1.41-2.04)^{\star \star \star}$ \\
\hline & SBA & $0.74(0.61-0.90)^{\star \star}$ & $0.88(0.74-1.06)$ & $0.71(0.59-0.85)^{\star \star *}$ & $0.83(0.70-1.00)^{*}$ \\
\hline \multirow{2}{*}{ Daily vegetables consumption } & VPA & $1.07(0.86-1.34)$ & $1.08(0.88-1.32)$ & $1.43(1.10-1.86)^{* *}$ & $1.55(1.27-1.88)^{* \star *}$ \\
\hline & SBA & $0.79(0.64-0.96)^{*}$ & $0.76(0.62-0.92)^{\star *}$ & $0.72(0.59-0.89)^{* *}$ & $0.94(0.79-1.13)$ \\
\hline \multirow{2}{*}{ Daily sweets consumption } & VPA & $1.04(0.86-1.27)$ & $0.95(0.80-1.13)$ & $0.99(0.78-1.26)$ & $0.94(0.77-1.14)$ \\
\hline & SBA & $1.28(1.07-1.53)^{\star *}$ & $1.41(1.19-1.68)^{\star \star *}$ & $1.57(1.28-1.92)^{* \star *}$ & $1.84(1.52-2.23)^{* \star *}$ \\
\hline \multirow{2}{*}{ Daily soft drinks consumption } & VPA & $0.99(0.81-1.21)$ & $0.99(0.82-1.19)$ & $0.88(0.69-1.12)$ & $0.80(0.64-1.00)$ \\
\hline & SBA & $1.82(1.50-2.20)^{* * *}$ & $1.95(1.62-2.35)^{\star \star *}$ & $1.86(1.51-2.30)^{\star \star *}$ & $2.33(1.88-2.89)^{\star * *}$ \\
\hline \multicolumn{6}{|l|}{ School related } \\
\hline \multirow{2}{*}{ Good perceived school achievement } & VPA & $1.02(0.83-1.25)$ & $1.06(0.88-1.28)$ & $1.23(0.99-1.52)$ & $1.24(1.03-1.49)^{*}$ \\
\hline & SBA & $0.66(0.55-0.80)^{* * *}$ & $0.62(0.51-0.74)^{\star \star \star}$ & $0.71(0.59-0.84)^{* \star *}$ & $0.76(0.64-0.91)^{\star \star}$ \\
\hline \multirow{2}{*}{ Liking school } & VPA & $1.11(0.91-1.35)$ & $0.99(0.83-1.19)$ & $1.16(0.92-1.47)$ & $1.00(0.80-1.24)$ \\
\hline & SBA & $0.61(0.50-0.73)^{\star \star *}$ & $0.65(0.54-0.78)^{* * *}$ & $0.67(0.55-0.82)^{\star \star *}$ & $0.76(0.62-0.93)^{\star *}$ \\
\hline \multirow{2}{*}{ Pressured by school } & VPA & $0.96(0.76-1.22)$ & $0.89(0.72-1.10)$ & $0.65(0.52-0.81)^{* * *}$ & $0.97(0.80-1.18)$ \\
\hline & SBA & $1.47(1.18-1.84)^{* * *}$ & $1.20(0.67-1.48)$ & $0.97(0.80-1.18)$ & $1.07(0.89-1.29)$ \\
\hline
\end{tabular}

${ }^{*} \mathrm{p}<0.05,{ }^{* *} \mathrm{p}<0.01,{ }^{* * *} \mathrm{p}<0.001$ 
Table 3. Interaction of country and age with vigorous physical activity (VPA) and screen-based activity (SBA) regarding risky behaviour, aggressive behaviour, eating habits, school-related outcomes concerned (only significant results are presented)

\begin{tabular}{|c|c|c|c|c|c|}
\hline & & \multicolumn{2}{|c|}{ Country } & \multicolumn{2}{|c|}{ Age } \\
\hline & & Boys & Girls & Boys & Girls \\
\hline & & OR $(95 \% \mathrm{Cl})$ & OR $(95 \% \mathrm{Cl})$ & OR $(95 \% \mathrm{Cl})$ & OR $(95 \% \mathrm{Cl})$ \\
\hline \multicolumn{6}{|l|}{ Risky behaviour } \\
\hline \multirow{2}{*}{ Smoking at least weekly } & VPA & - & - & - & - \\
\hline & SBA & $1.95(1.29-2.94)^{\star *}$ & $3.06(2.02-4.63)^{* * *}$ & - & $0.78(0.66-0.93)^{\star *}$ \\
\hline \multirow{2}{*}{ Lifetime drunkenness ( $\geq 2$ times) } & VPA & - & - & $1.20(1.07-1.34)^{* *}$ & - \\
\hline & SBA & - & - & - & $0.83(0.75-0.93)^{* *}$ \\
\hline \multicolumn{6}{|l|}{ Aggressive behaviour } \\
\hline \multirow{2}{*}{ Bullying others ( $\geq 2$ times a month) } & VPA & - & - & - & - \\
\hline & SBA & - & - & $0.82(0.71-0.95)^{* *}$ & $0.86(0.75-1.00)^{*}$ \\
\hline \multirow{2}{*}{ Frequent fighting ( $\geq 3$ times a year) } & VPA & $1.50(1.03-2.16)^{*}$ & - & - & - \\
\hline & SBA & $0.69(0.49-0.97)^{*}$ & - & - & - \\
\hline \multicolumn{6}{|l|}{ Eating habits } \\
\hline \multirow{2}{*}{ Regular breakfast on weekdays } & VPA & $1.44(1.08-1.93)^{*}$ & $1.43(1.11-1.84)^{* *}$ & - & - \\
\hline & SBA & - & - & - & $1.08(1.00-1.17)^{*}$ \\
\hline \multirow{2}{*}{ Daily fruit consumption } & VPA & $1.80(1.31-2.46)^{\star \star \star}$ & $1.57(1.21-2.03)^{\star * \star}$ & - & - \\
\hline & SBA & - & - & - & - \\
\hline \multirow{2}{*}{ Daily vegetables consumption } & VPA & - & $1.44(1.09-1.90)^{\star *}$ & - & - \\
\hline & SBA & - & - & - & - \\
\hline \multirow{2}{*}{ Daily sweets consumption } & VPA & - & - & - & - \\
\hline & SBA & - & $1.34(1.04-1.74)^{*}$ & $0.91(0.84-0.99)^{*}$ & - \\
\hline \multirow{2}{*}{ Daily soft drinks consumption } & VPA & - & $1.32(1.00-1.74)^{*}$ & - & - \\
\hline & SBA & - & - & - & - \\
\hline \multicolumn{6}{|l|}{ School related } \\
\hline \multirow{2}{*}{ Good perceived school achievement } & VPA & - & - & - & - \\
\hline & SBA & - & - & - & - \\
\hline \multirow{2}{*}{ Liking school } & VPA & - & - & - & - \\
\hline & SBA & - & - & - & - \\
\hline \multirow{2}{*}{ Pressured by school } & VPA & $0.67(0.49-0.93)^{*}$ & - & - & - \\
\hline & SBA & $0.68(0.51-0.91)^{\star *}$ & - & - & $0.86(0.79-0.94)^{* * *}$ \\
\hline
\end{tabular}

${ }^{*} p<0.05,{ }^{* *} p<0.01,{ }^{* * *} p<0.001$

consumption, but only among Czech adolescents. On the other hand, SBA decreased the probability of regular breakfast consumption, daily fruit consumption (only among boys and slightly among Czech girls) and daily vegetable consumption (only among girls and Czech boys) and increased the probability of daily sweet and soft drink consumption.

Czech girls who reported VPA also reported significantly more frequently good perceived school achievement and among boys also significantly less frequently being pressured by school. We did not confirm any other association of VPA with the explored school-related outcomes. On the contrary, SBA was shown to have an undesirable association with all school-related outcomes except school pressure in Czech boys and girls and Slovak girls.

Adjustment for SES was shown to be a non-significant step in the logistic regression model and did not significantly contribute to the association of VPA and SBA with the outcomes.
Statistically significant interactions of country and age with the explored outcomes can be found in Table 3. Significant interactions of country with VPA or SBA and their associations with the explored outcomes indicate a higher sensitivity among Czech adolescents compared with Slovak adolescents and the relationship of VPA with the explored outcomes. With respect to SBA the findings are less consistent. Significant interactions of age with VPA or SBA and their relationship with the explored outcomes indicate a higher sensitivity among younger age groups compared with 15-year-old adolescents and the association of VPA as well as SBA with the explored outcomes.

\section{DISCUSSION}

This study aimed to examine the associations of VPA and SBA with substance use (weekly smoking, life-time drunkenness), 
violent behaviour (bullying, fighting), dietary habits (regular breakfast consumption, daily fruit, vegetable, sweets and soft drinks consumption) and school-related outcomes (good perceived school achievement, attitude towards school, school stress) of school-aged children. Our results show that while VPA was positively associated with healthy development of adolescents, screen-based activity shows an inverse relationship, this is not related to the effect of age or SES on the examined outcomes. Children reporting SBA are more prone to report substance use, violent behaviour, unhealthy eating habits, and undesirable school-related outcomes.

Other studies have also shown a negative association of SBA with health-related behaviour. Janssen et al. (27) report a strong relationship between computer and video gaming and violence in youth. Lipsky and Iannotti (28) demonstrated that TV viewing was associated with a cluster of unhealthy dietary behaviours in US adolescents, such as skipping breakfast, sugary and soft drinks intake, intake of candy and fast food or low intake of fruit and vegetables. Similar results can also be found in other studies (29, 30 ). In addition, excessive TV watching is also associated with short sleep and morning tiredness in adolescents (31).

Our results show that SBA has significant associations with most school-related outcomes, such as good perceived school achievement, attitude towards school or school stress. This result is also supported by the study of Tremblay et al. (32) which shows that watching TV more than 2 hours a day was associated with decreased academic achievement and lower self-esteem in schoolaged children and youth. On the other hand, physical activity could improve the self-esteem and self-efficacy of youths (33).

Based on these findings it might be expected - and should be explored in further research - that a high level of SBA accompanied by skipping breakfast $(28,29)$, short sleep and morning tiredness (31) might show an inverse relationship with adolescents' capacity for school performance. This might be represented by feeling pressured by school and having less good perception of the school achievement, which might result in disliking school, thus negatively affecting educational aspirations.

Significant interactions of age with VPA or SBA in their association with the explored outcomes indicate a higher sensitivity among younger age groups in comparison with 15 years old adolescents to the association of VPA as well as SBA with the explored outcomes. Currie et al. (7) recommend interventions encouraging an increase in physical activity and reducing SBA, especially in younger adolescents. Thus our results imply that policies and interventions promoting health and physical activity should focus on younger age groups. Such measures might include items like introducing active school breaks (34) or a safe local environment (35) which seems to reduce SBA and stimulate VPA.

\section{Strengths and Limitations}

It is important to consider certain strengths and limitations of this study. An important strength is that we collected relevant data from a representative sample of adolescents from two countries of the age relevant for establishing health-related behaviour. A limitation of our study is that the results are based on self-reported data. However, self-reporting has been shown to offer satisfying reliability in terms of health-related behaviour (36). Moreover, the questionnaires were filled in anonymously and confidentiality was ensured. The main limitation, however, is the cross-sectional design of our study, which makes it impossible to formulate conclusive statements about causality in our findings. Therefore, they need to be confirmed by studies with a longitudinal design. Also, while the study includes two of the most prevalent SBAs, other behaviours contribute to total sedentary time which could potentially have different associations with the outcome measures.

\section{CONCLUSION}

SBAs show an inverse relationship with adolescent's healthy development, especially in the group of 11 and 13 years old children. VPA is positively associated with the development of adolescents. Reduction of screen-based activity in adolescents should be highlighted in health-promoting strategies and interventions in families, schools and communities as well as on higher levels of public health promoting policy.

\section{Acknowledgements}

This work was supported by the IGA UP research project "Leisure Time in School-aged Children - HBSC Study”, reg. No. FTK_2013_020 (40\%), the ECOP project "Strengthening the scientific potential of research teams in promoting physical activity at Palacký University" reg. No. CZ.1.07/2.3.00/20.0171 (40\%), and the Slovak Research and Development Agency under contract No. APVV-0032-11 (20\%).

\section{Conflict of Interest}

None declared

\section{REFERENCES}

1. Ng SW, Popkin BM. Time use and physical activity: a shift away from movement across the globe. Obes Rev. 2012 Aug;13(8):659-80.

2. World Health Organization. The world health report: 2002: reducing risks, promoting healthy life. Geneva: WHO; 2002.

3. Finucane MM, Stevens GA, Cowan MJ, Danaei G, Lin JK, Paciorek CJ, et al.; Global Burden of Metabolic Risk Factors of Chronic Diseases Collaborating Group (Body Mass Index). National, regional, and global trends in body-mass index since 1980: systematic analysis of health examination surveys and epidemiological studies with 960 country-years and 9·1 million participants. Lancet. 2011 Feb 12;377(9765):557-67.

4. Knuth AG, Hallal PC. Temporal trends in physical activity: a systematic review. J Phys Act Health. 2009 Sep;6(5):548-59.

5. Wang Y, Lobstein T. Worldwide trends in childhood overweight and obesity. Int J Pediatr Obes. 2006;1(1):11-25.

6. Sigmundová D, Sigmund E, Hamrik Z, Kalman M. Trends of overweight and obesity, physical activity and sedentary behaviour in Czech schoolchildren: HBSC study. Eur J Public Health. 2014 Apr;24(2):210-5.

7. Currie C, Zanotti C, Morgan A, Currie D, De Looze M, Roberts C, et al., editors. Social determinants of health and well-being among young people: Health Behaviour in School-aged Children (HBSC) study: international report from the 2009/2010 survey. Health policy for children and adolescents, no. 6. Copenhagen: WHO Regional Office for Europe; 2012.

8. Bradley CB, McMurray RG, Harrell JS, Deng S. Changes in common activities of 3rd through 10th graders: the CHIC study. Med Sci Sports Exerc. 2000 Dec;32(12):2071-8.

9. Lobstein T, Frelut ML. Prevalence of overweight among children in Europe. Obes Rev. 2003 Nov;4(4):195-200.

10. Ogden CL, Carroll MD, Kit BK, Flegal KM. Prevalence of obesity and trends in body mass index among US children and adolescents, 19992010. JAMA. 2012 Feb 1;307(5):483-90.

11. Daniels SR, Arnett DK, Eckel RH, Gidding SS, Hayman LL, Kumanyika S, et al. Overweight in children and adolescents: pathophysiol- 
ogy, consequences, prevention, and treatment. Circulation. 2005 Apr 19;111(15):1999-2012.

12. Dietz WH. Health consequences of obesity in youth: childhood predictors of adult disease. Pediatrics. 1998 Mar;101(3 Pt 2):518-25.

13. Gortmaker SL, Must A, Perrin JM, Sobol AM, Dietz WH. Social and economic consequences of overweight in adolescence and young adulthood. N Engl J Med. 1993 Sep 30;329(14):1008-12.

14. Singh AS, Mulder C, Twisk JW, van Mechelen W, Chinapaw MJ. Tracking of childhood overweight into adulthood: a systematic review of the literature. Obes Rev. 2008 Sep;9(5):474-88.

15. Iannotti RJ, Janssen I, Haug E, Kololo H, Annaheim B, Borraccino A; HBSC Physical Activity Focus Group. Interrelationships of adolescent physical activity, screen-based sedentary behaviour, and social and psychological health. Int J Public Health. 2009 Sep;54 Suppl 2:191-8.

16. Hallal PC, Andersen LB, Bull FC, Guthold R, Haskell W, Ekelund U; Lancet Physical Activity Series Working Group. Global physical activity levels: surveillance progress, pitfalls, and prospects. Lancet. 2012 Jul 21;380(9838):247-57.

17. Pratt M, Macera CA, Blanton C. Levels of physical activity and inactivity in children and adults in the United States: current evidence and research issues. Med Sci Sports Exerc. 1999 Nov;31(11 Suppl):S526-33.

18. Biddle SJ, Gorely T, Marshall SJ, Cameron N. The prevalence of sedentary behavior and physical activity in leisure time: A study of Scottish adolescents using ecological momentary assessment. Prev Med. 2009 Feb;48(2):151-5.

19. Sigmundová D, El Ansari W, Sigmund E, Frömel K. Secular trends: a ten-year comparison of the amount and type of physical activity and inactivity of random samples of adolescents in the Czech Republic. BMC Public Health. 2011 Sep 26;11:731. doi: 10.1186/1471-2458-11-731.

20. Mark AE, Janssen I. Relationship between screen time and metabolic syndrome in adolescents. J Public Health (Oxf). 2008 Jun;30(2):153-60.

21. Salmon J, Tremblay MS, Marshall SJ, Hume C. Health risks, correlates, and interventions to reduce sedentary behavior in young people. Am J Prev Med. 2011 Aug;41(2):197-206.

22. Erikson EH. Identity and the life cycle. New York: Norton; 1980.

23. van Nieuwenhuijzen M, Junger M, Velderman MK, Wiefferink KH, Paulussen TW, Hox J, et al. Clustering of health-compromising behavior and delinquency in adolescents and adults in the Dutch population. Prev Med. 2009 Jun;48(6):572-8.

24. Flay BR. Positive youth development requires comprehensive health promotion programs. Am J Health Behav. 2002 Nov-Dec;26(6):407-24.

25. Roberts C, Freeman J, Samdal O, Schnohr CW, de Looze ME, Nic Gabhainn S, et al.; International HBSC Study Group. The Health Behaviour in School-aged Children (HBSC) study: methodological developments and current tensions. Int J Public Health. 2009 Sep;54 Suppl 2:140-50.
26. Currie C, et al. Health Behaviour in School-aged Children (HBSC) study protocol: background, methodology and mandatory items for the 2009/2010 survey. Edinburgh: CAHRU; 2011.

27. Janssen I, Boyce WF, Pickett W. Screen time and physical violence in 10 to 16-year-old Canadian youth. Int J Public Health. 2012 Apr;57(2):32531.

28. Lipsky LM, Iannotti RJ. Associations of television viewing with eating behaviors in the 2009 Health Behaviour in School-aged Children Study. Arch Pediatr Adolesc Med. 2012 May;166(5):465-72.

29. Pearson N, Ball K, Crawford D. Mediators of longitudinal associations between television viewing and eating behaviours in adolescents. Int $\mathrm{J}$ Behav Nutr Phys Act. 2011 Mar 30;8:23. doi: 10.1186/1479-5868-8-23.

30. Al-Hazzaa HM, Abahussain NA, Al-Sobayel HI, Qahwaji DM, Musaiger AO. Physical activity, sedentary behaviors and dietary habits among Saudi adolescents relative to age, gender and region. Int J Behav Nutr Phys Act. 2011 Dec 21;8:140. doi: 10.1186/1479-5868-8-140.

31. Ortega FB, Chillón P, Ruiz JR, Delgado M, Albers U, Alvarez-Granda JL, et al. Sleep patterns in Spanish adolescents: associations with TV watching and leisure-time physical activity. Eur J Appl Physiol. 2010 Oct;110(3):563-73.

32. Tremblay MS, LeBlanc AG, Kho ME, Saunders TJ, Larouche R, Colley $\mathrm{RC}$, et al. Systematic review of sedentary behaviour and health indicators in school-aged children and youth. Int J Behav Nutr Phys Act. 2011 Sep 21;8:98. doi: 10.1186/1479-5868-8-98.

33. Veselska Z, Madarasova Geckova A, Reijneveld SA, van Dijk JP. Aspects of self differ among physically active and inactive youths. Int J Public Health. 2011 Jun;56(3):311-8.

34. Groffik D, Sigmund E, Frömel K, Chmelík F, Nováková Lokvencová P. The contribution of school breaks to the all-day physical activity of 9- and 10-year-old overweight and non-overweight children. Int J Public Health. 2012 Aug;57(4):711-8.

35. Biddle SJ, Gorely T, Marshall SJ, Murdey I, Cameron N. Physical activity and sedentary behaviours in youth: issues and controversies. J R Soc Promot Health. 2004 Jan;124(1):29-33.

36. Del Boca FK, Noll JA. Truth or consequences: the validity of self-report data in health services research on addictions. Addiction. 2000 Nov;95 Suppl 3:S347-60.

Received November 15, 2014 Accepted in revised form August 9, 2015 